\title{
Discussion to papers of Dr Lindan et al., Dr Frankel and Dr Mathias
}

\author{
Chairman: Dr Dollfus
}

Dr Carter (U.S.A.). I'd like to know from Dr Frankel what type of stimulus does an electro-ejaculator give?

DR FRANKEL (G.B.). Our ejaculator is very primitive, it's a sinusoidal current of 50 Hertz, it's not the most efficient current. It comes off the mains which is connected to the national grid which is connected across the channel to the French national grid and therefore at certain times of the day we will of course be receiving French electricity.

Dr MADERSBACHER (Austria). I would just ask Dr Frankel to say a few words about the quality of the semen you got in these patients where they were successful in their ejaculation.

Dr Frankel. We don't look at the chemistry of our semen, we look at it under the microscope and these were dead sperms that we received on both occasions.

Dr Rosemary Lindan (U.S.A). We have not used trinitrine but we are considering doing some tests with this but I am not sure that we can use it on electronic basis. I'd like to ask Dr Frankel when is the time to do this electro stimulation. Should it be at the time of injury, when you can obtain the sperm from the newly injured male and freeze it because we've had questions from tetraplegics as to whether they will ever be able to father a child and we felt badly that nothing had been done to obtain a specimen at the time when there would be still a reasonable supply of sperm.

DR FrANKel. Yes we do use trinitrin widely mainly as a drug for the patient to administer to himself so there is something the patients themselves can take without an injection as long as they are recumbent. When they take it it is effective for a few minutes. With regard to the second question, it is our policy to try and obtain semen not just from tetraplegics but from all spinal injury cases that are complete lesions at an early stage. We do have access to the deep freeze. 